\title{
Qualitative and Quantitative Determination of Montmorillonite Using Infrared Spectrometry
}

\author{
A.F. Altzoumailis ${ }^{\mathrm{a}, *}$, V. N. Kytopoulos ${ }^{\mathrm{b}}$ \\ ${ }^{\text {a }}$ School of Chemical Engineering, National Technical University of Athens,5 Heroes of \\ Polytechnion, 15773 Athens, Greece, e-mail: ajumaily@central.ntua.gr \\ ${ }^{\mathrm{b}}$ School of Applied Mathematical and Physical Sciences, National Technical University of \\ Athens, 5 Heroes of Polytechnion, 15773 Athens, Greece
}

Received: June 16, 2021. Revised: November 13, 2021. Accepted: November 30, 2021. Published: December $26,2021$.

\begin{abstract}
The present study investigates the various possibilities of qualitative and quantitative analysis of montmorillonite (1/2Ca, Na) 0.7 (Al, $\mathrm{Mg}, \mathrm{Fe}) 4$ ( $\mathrm{Si}, \mathrm{Al})$ 8020 (OH) 4. $n \mathrm{H}_{2} \mathrm{O}$ (MT), major constituent of Bendonite coming the island Milos-Greece, using infrared (IR) spectroscopy and preparing the samples with KBr. X-Ray diffraction diagrams were obtained for the determination of their mineralogical composition. Observation of IR spectra of sample with different MT content revealed that the $\mathrm{Si}-\mathrm{O}-\mathrm{Si}$ vibration band at $1038 \mathrm{~cm}^{-1}$ sharpens with increasing MT content. The combination of the above techniques led to a convenient determination of the minerals, contained in the sample and to a discrimination of identical oscillations, observed in different minerals at the same wave number $\left(1038 \mathrm{~cm}^{-1}\right)^{[1]}$. As far as the quantitative analysis concerns, in the case of MT, thirteen comparative samples of known composition were analysed. The obtained spectra were digitized and smoothed, within the area from 800 to $1200 \mathrm{~cm}^{-1}$, using the Savitzky - Golay method, followed by Lorentz function transformation. Due to overlap from other substances, the plot of a calibration curve for MT, and consequently the development of a model, describing the absorption / concentration correlation for a specific sample, were not satisfactory. So the calibration curve according to Lambert- Beer law ${ }^{[2,3]}$, required use of samples with high concentration of MT. To overcome this problem the calibration curve for MT was constructed using dilutions of standard samples containing more than $85 \%$ of the mineral, with $\mathrm{SiO}_{2}$, at the wave number of $1038 \mathrm{~cm}^{-1}$. This curve was used for the determination of MT in unknown samples giving very good results compared with the mineralogical composition obtained by XRD.
\end{abstract}

Keywords: IR, MT, XRD, Savitzky Golay, LampertBeer, Lorentz, Kbr.

\section{INTRODUCTION}

Infrared spectrometry is one of the most popular instrumental methods of analysis, allowing the analysis of physical parameters of different materials and it is based on the vibrations of the bonds of ionic lattice compounds. The qualitative and quantitative analysis of various minerals, using IR- analysis has been the subject of great scientific interest. However, the great majority of relative references came from the decade of 1950 , mainly due to the rapid development of sophisticated analytical methods. Thus, Sholze H. (1960) shown that the water peak area is presented in $3 \mu$ vibration (caused by $\mathrm{OH}$ vibration), the deforming $\mathrm{H}_{2} \mathrm{O}$ vibration in $6 \mu$ and the combination of the two mentioned vibrations at $1.93 \mu$. If water exists in its molecular form the peak area of $6 \mu$ is interfered by other peak areas. For quantitative analysis the choice of the lowest wavelength is preferable, especially at low concentrations of water. R. Fisher and C. Ring (1957) determined quantitatively fluoroapatite and hydroxyapatite in the range of $16 \mu$, with $1.5 \%$ mean of error as for fluoroapatite. J. Hynt and D. Tyrner (1953) shown that two different kinds of element replacements ca exict in trioctaedrical minerals. The first involves the replacement of a simple ion from other, such as $\mathrm{Ni}^{2+}$ and $\mathrm{Mg}^{2+}$ in talk mineral. The second involves a double replacement of equal electric charge, such as $\mathrm{Si}^{4+}$ from $\mathrm{Al}^{3+}$ and $\mathrm{Na}^{+}$. Stubcan and Roy (1959) shown the peak area of dioctaedrical and trioctaedrical complex minerals in the range of $400-5000 \mathrm{~cm}^{-1}$ and characteristic changes in their IR-spectrum were observed.

In the present work the possibility of the qualitative and quantitative analysis of montmorillonite was investigated and evaluated.

\section{Instrumentation}

\section{EXPERIMENTAL}

For the IR analysis of the samples the IRspectrometer Perkin-Elmer 883 was used. The study of the samples structure was achieved using the Siemens 5000D- XRD spectrometer and for the sample preparation a specific press instrument SPECAC (Perkin Elmer) was used.

Reagents

All samples came from Milos Island, Greece, as it is presented in Table 1, while $\mathrm{KBr}$ was supplied by CARLO ERBA.

\section{ANALYTICAL PROCEDURE}

All samples that are presented in Table 1 underwent a decrease of their size, so as to have 
the suitable one for IR-analysis. The samples were diluted with $\mathrm{KBr}$ in a proportion $\mathrm{KBr}$ : sample 1.5: $200 \mathrm{mg}$ and by applying $7 \mathrm{Atm}$ pressure using the SPECAC press were converted into a pellet. After analyzing the samples using IR spectroscopy, the obtained spectrums were first qualitatively evaluated. For the correct quantitatively determination is the absence of various interferences of the same wavelengths from other minerals and, consequently, the total mineral qualitative analysis before the IR-analysis, as it is presented in Table 2, is necessary. However, the kind of element replacements in various syntactic areas of mineral crystallite should be investigated, for the correct evaluation of possible interferences in the peak areas or the removal of the zone. The characteristic zones of montmorillonites are: 3225, 115-1009, 1038-1026, 915, 878, 845-835, $797-790,623,522$ and $467 \mathrm{~cm}^{-1}$. Calcite gives a peak at $1400 \mathrm{~cm}^{-1}$, while the corresponding one of quartz is $798-400 \mathrm{~cm}^{-1}$ and kaolinite at 3698 and $915 \mathrm{~cm}^{-1}$ (sample No 18). For low concentrations doublet quartz gives a single zone at $796-800 \mathrm{~cm}^{-1}$ and because of the low $\mathrm{Fe}$ content $\left(\mathrm{Fe}_{2} \mathrm{O}_{3}<10 \%\right)$ the characteristic zone of $\mathrm{Fe}-\mathrm{O}-\mathrm{H}$ at $3576 \mathrm{~cm}^{-1}$ is absence. The zone presented at $3200-3250 \mathrm{~cm}^{-1}$ is caused of the present of water molecules, which are highly bonded with montmorillonite surface. XRD-analysis, which was carried out, determined, apart from montmorillonite, alternative concentrations of quartz, crystoballite, albite, orthoclase, illite and kaolinite.

\begin{tabular}{|l|l|l|}
\hline Sample's name & Sample species & Place of sample \\
\hline M-1207 & Bendonite & Milos-Greece \\
\hline & & \\
\hline M-1211 & Bendonite & Milos-Greece \\
\hline M-1201 & Bendonite & Milos-Greece \\
\hline M-1202 & Bendonite & Milos-Greece \\
\hline M-14 & Bendonite & Milos-Greece \\
\hline M-1004 & Bendonite & Milos-Greece \\
\hline M-18 & Bendonite & Milos-Greece \\
\hline M-21 & Bendonite & Milos-Greece \\
\hline M-22 & Bendonite & Milos-Greece \\
\hline M-10 & Bendonite & Milos-Greece \\
\hline M-8 & Bendonite & Milos-Greece \\
\hline M-75 & Bendonite & Milos-Greece \\
\hline
\end{tabular}

Table 1: Source of samples

\begin{tabular}{|c|c|c|c|c|c|c|c|c|c|c|c|c|}
\hline Dried Sample & M-1207 & M-1211 & M-1201 & M-1202 & M-14 & M-1004 & M-18 & M.75 & M.21 & M-10 & M.8 & M-1204 \\
\hline $\mathrm{SiO}_{2}$ & 74,36 & 67,56 & 62,16 & 63,40 & 69,22 & 47,36 & \begin{tabular}{|l|}
55,01 \\
\end{tabular} & \begin{tabular}{|l|}
52,01 \\
\end{tabular} & \begin{tabular}{|l|l|}
51,58 \\
\end{tabular} & \begin{tabular}{|l|l|}
59,44 \\
\end{tabular} & \begin{tabular}{|l|l|}
53,69 \\
\end{tabular} & \begin{tabular}{|l|l|}
68,72 \\
\end{tabular} \\
\hline $\mathrm{SO}_{3}$ & 0,06 & 0,74 & 3,15 & 0,07 & 0,90 & 2,54 & 0,15 & \begin{tabular}{|l|}
0,07 \\
\end{tabular} & \begin{tabular}{|l|l|}
0,22 \\
\end{tabular} & . & & 0,05 \\
\hline $\mathrm{Fe}_{2} \mathrm{O}_{3}$ 'tot & 0,76 & 1,21 & 4,96 & 1,94 & 2,39 & 5,08 & 4,60 & \begin{tabular}{|l|}
4,69 \\
\end{tabular} & 2,25 & 4,71 & 5,77 & 1,08 \\
\hline $\mathrm{Al}_{2} \mathrm{O}_{3}$ & 9,52 & 11,97 & 9,45 & 13,06 & 16,33 & 15,52 & 22,30 | & \begin{tabular}{|l|l|}
16,84 \\
\end{tabular} & \begin{tabular}{|l|}
18,76 \\
\end{tabular} & \begin{tabular}{|l|l|}
19,97 \\
\end{tabular} & \begin{tabular}{|l|}
19,90 \\
\end{tabular} & 11,63 \\
\hline $\mathrm{CaO}$ & 0,92 & 0,69 & 0,76 & 1,05 & 1,15 & 0,89 & 1,46 & \begin{tabular}{|l|}
2,40 \\
\end{tabular} & \begin{tabular}{|l|}
8,44 \\
\end{tabular} & 2,42 & \begin{tabular}{|l|l|}
4,11 \\
\end{tabular} & 1,15 \\
\hline MgO & 0,82 & 1,15 & 1,72 & 2,26 & 1,92 & 2,67 & \begin{tabular}{|l|}
3,12 \\
\end{tabular} & 4,11 & & $\begin{array}{l}3,63 \\
\end{array}$ & \begin{tabular}{|l|}
3,10 \\
\end{tabular} & 0,85 \\
\hline $\mathrm{K}_{2} \mathrm{O}$ & 0,71 & 3,58 & 1,08 & 0,18 & 0,96 & 0,96 & 4,13 & \begin{tabular}{|l|}
1,28 \\
\end{tabular} & \begin{tabular}{|l|}
0,51 \\
\end{tabular} & 0,36 & \begin{tabular}{|l|}
0,55 \\
\end{tabular} & 1,67 \\
\hline $\mathrm{Na}_{2} \mathrm{O}$ & 0,40 & 0,35 & 0,43 & 0,29 & 0,66 & 0,37 & \begin{tabular}{|l|}
0,70 \\
\end{tabular} & \begin{tabular}{|l|}
1,47 \\
\end{tabular} & \begin{tabular}{|l|}
0,71 \\
\end{tabular} & 1,47 & \begin{tabular}{|l|}
0,86 \\
\end{tabular} & 1,06 \\
\hline $\mathrm{TiO}_{2}$ & 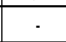 & . & 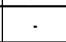 & . & 0,16 & . & \begin{tabular}{|l|}
0,66 \\
\end{tabular} & . & \begin{tabular}{|l|}
0,66 \\
\end{tabular} & 0,56 & 0,56 & . \\
\hline Loss of firing & 12,70 & 10,65 & 15,89 & 16,54 & 6,75 & 21,65 & 8,10 & 16,52 & 13,20 & 7,53 & 11,11 & 13,16 \\
\hline Total & 100,26 & 97,89 & 99,60 & 98,79 & 99,47 & 97,04 & 100,90 & 99,40 & 99,11 & 100,90 & 99,65 & 99,38 \\
\hline Ilite & 3,5 & 37,7 & & & 17,00 & & & 11,00 & 4,5 & 3,00 & 5,00 & \\
\hline Montmorillonite & 41,00 & 28,00 & $\begin{array}{l}6,00 \\
\end{array}$ & 65,00 & 32,00 & 76,00 & 70,00 & 54,00 & 86,00 & 81,00 & 88,00 & 41,00 \\
\hline Kaolinite & 3,00 & IXNH & & & 7,00 & & & & & & & \\
\hline $\begin{array}{l}\text { Quartz + } \\
\text { Cristobalite }\end{array}$ & 56,00 & 39,00 & 40,00 & 35,00 & 38,00 & 20,00 & 2,00 & 24,00 & & 5,00 & & 41,00 \\
\hline Alvitis & & & 4,00 & & 6,00 & & 6,00 & 11,00 & & 13,00 & & 9,00 \\
\hline Calcite & $\mathrm{IXNH}$ & IXNH & 1,00 & IXNH & IXNH & $\mathrm{IXNH}$ & IXNH & IXNH & 15,00 & IXNH & \begin{tabular}{|l|}
7,00 \\
\end{tabular} & IXNH \\
\hline Gypsum & & & & & & 5,00 & & & & & & \\
\hline K-feldsty & & & & & & & 22,00 & & & & & 9,00 \\
\hline Hematite & & & & & & & & & & & & \\
\hline
\end{tabular}

Table 2: Chemical and Mineral composition of analyzed Bentonite samples (Wt \%)

\section{RESULTS AND DISCUSSION}

The vibrations in clay minerals can be categorized in the vibrations of $\mathrm{OH}, \mathrm{Si}$, octaedrical cations and internal cations. This categorization is complete for the high frequency stretching vibrations of $\mathrm{OH}$, found in the area of $3400-3750 \mathrm{~cm}^{-1}$, but not for the stretching vibrations $\mathrm{Si}-\mathrm{O}\left(700-1200 \mathrm{~cm}^{-1}\right)$ that are over-right from other vibrations but the bending vibrations $\mathrm{Si}-\mathrm{O}\left(200-600 \mathrm{~cm}^{-1}\right)$ that are over-right strongly from vibrations of octahedral cations and from vibrations of displacement of the $\mathrm{OH}$ group. The vibrations of the internal cations by the V.C. Farmer, found between 70 and $150 \mathrm{~cm}^{-1}$ can be proven to be topical, despite the fact of the possible interaction with the less strong deformations of $\mathrm{Si}$ anion. Montmorillonite is a mineral with a structure of 2:1 and its chemical form is: $\mathrm{Al}$, $\mathrm{Fe}, \mathrm{Mg})_{2}(\mathrm{OH})_{2} \mathrm{I}(\mathrm{Si}, \mathrm{Al})_{4}(\mathrm{O}, \mathrm{OH})_{10} \mathrm{~K}\left(\mathrm{~K}^{+}\right.$, $\mathrm{Ca}^{2+}, \mathrm{Mg}^{2+}$, the characteristic zones of montmorillonite are $3624,3420,3225,1115$ $1090,1038-1026,915,878,845-835,797-$ $790,623,522,467 \mathrm{~cm}^{-1}$.

The calcite can be seen at $1400 \mathrm{~cm}^{-1}$, the quartz in the area of $798-400 \mathrm{~cm}^{-1}$ and the kaolinite at 3698 and $915 \mathrm{~cm}^{-1}$ (sample M-18). For very small concentrations the couple of peaks in the film of quartz is limited in a simple zone at 798 to $800 \mathrm{~cm}^{-1}$. Because of the small concentration of the samples in $\mathrm{Fe}$ 
$\left(\mathrm{Fe}_{2} \mathrm{O}_{3}<10 \%\right)$, there is not any zone at 3576 $\mathrm{cm}^{-1}$ due to $\mathrm{Fe}-\mathrm{O}-\mathrm{H}$. The zone that is present at $3200-3250 \mathrm{~cm}^{-1}$ is a result of the water molecules that are strongly connected with the surface of montmorillonite. The analysis that was carried out with X-Ray Diffraction (fig) determined except the montmorillonite some alternative concentrations of quartz, crystoballite, alvite, orthoclase, illite and kaolinite. The characteristic zones of montmorillonite are: $3624,3420,3225,1630$, 1038-1026, 915, 845-835, and $522 \mathrm{~cm}^{-1}$. The characteristic zones of illite are: 3643,3622 , $1080,1022,912,875,830,752,692,523,475$ $\mathrm{cm}^{-1}$. The characteristic zones of gypsum are: $3543,3485,3240,1685,1620,1162,1142$, $1112,668,606 \mathrm{~cm}^{-1}$. The characteristic zones of alvite are: 1150, 1096, 1035, 995, 786, 760, $744,650,594,536,467,428 \mathrm{~cm}^{-1}$. The characteristic zones of aimatite are: 600, 463, $425 \mathrm{~m}^{-1}$. The characteristic zones of quartz are: $1172,1082,798,778,693,512,478,460$ $\mathrm{cm}^{-1}$. The characteristic zones of crystoballite are: 1200, 1166, 1098, 792, 622, 520, 488, $476,445 \mathrm{~cm}^{-1}$.

Infrared spectrums of the analyzed samples of bentonite. The five diagrams given above between others have small concentrations of montmorillonite and the rest have high concentrations. The concentration optically can be seen from the opening of the shoulder of the wave numbers 1026, 1038, 1090 and $1115 \mathrm{~cm}^{-1}$. In the wave numbers $474,522,915,1026,1038,3420$ and $362 \mathrm{~cm}^{-1}$, the

Vibrations of Si-O, Si-O-Al, Al-O-H, Si-O-Si, $\mathrm{Si}-\mathrm{O}-\mathrm{Si}, \quad \mathrm{H}-\mathrm{O}-\mathrm{H}, \quad(\mathrm{Mg}, \mathrm{Al})-\mathrm{O}-\mathrm{H}$ are given respectively.

\begin{tabular}{ll}
\hline Wavelength $\left(\mathrm{cm}^{-1}\right)$ & Vibration \\
\hline 3642 & (Mg, Al)...O-H \\
3624 & Al...O-H \\
3420 & H-O-H \\
3225 & H-O-H \\
1630 & H-O-H \\
1168 & Si-O \\
$1115-1090$ & Si-O \\
915 & Al...O-H \\
878 & (Al, Fe)..O-H \\
$845-835$ & (Al, Mg)...O-H \\
796 & (Al, Mg)...-H \\
695 & Si-O-Al \\
623 & Al...O-H \\
578 & Al...O-H \\
522 & Si-O-Al \\
474 & Si-O \\
467 & Si-O-Mg \\
450 & Si-O-Fe \\
426 & Si-O \\
\hline
\end{tabular}

Table 3: Vibration wavelength in IR spectrum of montmorillonite

\section{CONCLUSION}

The qualitative as well as the quantitative analysis of montmorillonites is possible only if the mineralogical composition of the samples has been identified, which can be achieved using XRD spectrometry or electronic microscopy. Elementary analysis is substantial for the identification of the elements, which take part in the vibration giving information for elements' replacements in the mineral's crystal structure. Elements' replacements cause changes in the transmittance values and, as a result, errors in the quantitative evaluation. In case of montmorillonite:

- A low concentration of $\mathrm{MgO}$ makes $915 \mathrm{~cm}^{-1}$ zone become less separable from the main zone of $1028 \mathrm{~cm}^{-1}$, contrary to when the concentration of $\mathrm{MgO}$ is higher. In the latter case this separation is good.

- The zone of 1028 and $1038 \mathrm{~cm}^{-1}$ tend to form "shoulder" between them, whose size is reversely proportional to the montmorillonite concentration. Therefore, it is possible 2 comparative calibration curves of $0-50 \%$ and $50-100 \%$ montomorillonite concentration, respectively, to be obtained for the grouping of montmorillonite samples. 


\section{REFERENCES}

>1@ Arnold M A 1996 Noninvasive glucose monitoring Curr. Opin. Biotechnol. 7 469

>2@ Beebe K R and Kowalski B R 1987 An introduction to multivariate calibration and analysis Anal. Chem. 59 A1007-17

3@ Bhandare P, Mendelson Y, Peura R A, Janatsch G, Kruse-Jarres J, Marbach R and Heise H M 1993 Multivariate determination of glucose in whole-blood using partial least-squares and artificial neural networks based on midinfrared spectroscopy Appl. Spectrosc. 8 1214-21

24]. Budinova G, Salva J and Volka K 1997 Application of molecular spectroscopy in the mid-infrared region to the determination of glucose and cholesterol in whole blood and in blood serum Appl. Spectrosc. 51 631-5

>5]. Buslov D K, Nikonenko N A, Sushko N I and Zhbankov R G 1999 Analysis of the results of $\alpha$-D-glucose Fourier transform infrared spectrum de-convolution: comparison with experimental and theoretical data Spectrochim. Acta 55 229-38

>6]. Haaland D M, Robinson,MR, Koepp GW, Thomas E V and Eaton R P 1992

Reagentless near-infrared determination of glucose in whole-blood using multivariate calibration Appl. Spectrosc. $461575-8$

77. Hazen K H, Arnold M A and Small GW1998 Measurement of glucose and other analytes in undiluted human serum with near-infrared transmission spectroscopy Ann. Chim. Acta 371 25567

>87. Heise H M and Bittner A 1997 Rapid and reliable spectral variable selection for statistical calibrations based on PLSregression vector choices Fresenius's $J$. Anal. Chem. 359 93-9

>9]. Kacurakova M and Mathlouthi M 1996 FTIR and laser-Raman spectra of oligosaccharides in water: characterization of the glyosidic bonds Carbohydr. Res. 284 145-57
>10]. Petibois C, Cazorla G, Cassaigne A and Deleris G 2001 Plasma Protein content determined by Fourier-transform infrared spectrometry Clin. Chem. 47 730-8

>11]. Shamoon H et al 1993 the effect of intensive treatment of diabetes on the development and progression of long-term complications in insulin-dependent diabetes mellitus N. Engl. $J$.

>12]. Pecsok /Shieds /Cairns/Mc William (1981): Modern Methods of Chemichal Analysis. Second Edition London.

>13]. Van Der Marel H.W. and Beutelspacher H. (1976): Atlas of Infrared Spectroscopy of Clay Minerals and their Admixtures. Elsevier Amsterdam.

>14]. Deng Y., White N.Dixon J., 2002: Effect of Structual Stress on the Intercalation Rate of Kaolinite. Journal of Colloid and Intrface Science 250, 379-393.

\section{Creative Commons Attribution License 4.0 (Attribution 4.0 International, CC BY 4.0)}

This article is published under the terms of the Creative Commons Attribution License 4.0

https://creativecommons.org/licenses/by/4.0/deed.en_US 